\title{
Propuesta para el establecimiento de Sistemas Normalizados de Almacenaje para material arqueológico en museos
}

\author{
José Ángel Palomares Samper \\ Técnico conservador de Arqueología \\ Museo de Cádiz
}

\begin{abstract}
Resumen
El almacenamiento de material arqueológico, control del mismo y gestión de sus movimientos internos y externos es uno de los más importantes problemas que poseen los profesionales del museo, en ocasiones actuando de forma improvisada ante la incesante llegada de material. Por ello, dedicamos este artículo a la presentación de un documento interno que evalúe de antemano las características de las reservas de nuestro museo, su capacidad espacial y técnica, y sistematice las herramientas documentales de control de éstas y normalice la cumplimentación de éstos y las tareas a seguir: un Sistema Normalizado de Almacenaje.
\end{abstract}

\section{Palabras claves}

Reserva; Almacén / Documento / Sistematización / Normalización / Referencia Topográfica / Nomenclator

\section{Introducción}

En la actualidad, la doctrina museológica se encuentra mucho más centrada en su interés por las funciones sociales que el museo cumple como institución de carácter no lucrativo abierta al público, que en la praxis museográfica con la que diariamente nos enfrentamos los profesionales del museo. Ello se deriva de la redefinición de la esencia de los museos de corte occidental en la segunda mitad del siglo $X X$, que desvía su interés del objeto museable hacia el público museístico. Es éste último quien da razón de ser al museo, cuyas funciones y servicios se defi- nen siempre en relación al público real o virtual -"futuras generaciones"- usuario de sus colecciones, instalaciones y material específicamente museológico y didáctico.

Esta situación no se cuestiona en estas páginas, pues las elucubraciones museológicas son necesarias para el desarrollo de ésta como ciencia social del museo, y marcan un importante sendero teorético por el que la práctica puede transitar con niveles de calidad y efectividad óptimos. Lo que pretendemos subrayar en estas palabras preliminares al tratamiento de los problemas de almacenaje y gestión de las reservas en museos arqueológicos o mixtos es la necesidad de que los profesionales comuniquemos nuestras experiencias en la tarea diaria de enfrentar problemas concretos, y exponer y confrontar aquellas soluciones que experimentamos o intentamos probar en nuestros centros de trabajo, los museos, no importa su titularidad, tamaño o disciplina. Por nimia que nos parezca la idea a poner en común, nuestro deber es exponerla, pues el nuevo conocimiento sólo se adquiere mediante el reconocimiento de su carencia y la necesidad de obtenerlo. El debate siempre será fructífero.

\section{Problema de almacenaje de material arqueológico} en museos

Uno de los problemas con los que nos enfrentamos diariamente los conservadores y demás técnicos de los museos es la recepción, documentación y almacenaje del numerosísimo material arqueológico que llega a nuestros museos. La legislación nacional y autónoma vigente reconoce al patrimonio arqueológico su carácter de bien de dominio público, por lo que el tráfico legal de este tipo de material exhumado prácticamente se ha erradicado, manteniéndose en concretas colecciones privadas de carácter histórico o material legalmente reconocido como propiedad privada de algún coleccionista, aficionado o particular. Así, todo material exhumado en campañas arqueológicas autorizadas, hallazgos casuales o ma- 
terial incautado por las fuerzas de seguridad del estado debe ser devuelto al dominio público, siendo su natural depositario los centros de tutela patrimonial de carácter público o privado reconocidos por la Administración Pública. En la práctica usual, los museos.

Dependiendo de lo que establezca la administración competente en la concesión del permiso previo a la campaña de excavación, se designa el centro de tutela de los materiales obtenidos por este procedimiento, que se incorporarán a la colección estable del museo, engrosando sus colecciones (aunque en el caso actual, las piezas se incorporen con carácter de depósitos de la Administración gestora en los museos de titularidad estatal, a pesar de constituir parte de su colección estable).

Este proceso, que en teoría se describe tan escuetamente, se concreta en un innumerable desfile de cajas, cajones y piezas de grandes dimensiones y peso elevado que van llegando al museo, con el consiguiente alivio de aquellos profesionales que encuentran cumplido su cometido con su entrega y el calvario que comienza para el profesional de los museos que debe ubicar en tránsito este material, hasta que llegue el momento de revisarlo, registrarlo, inventariarlo, documentarlo y darle un valor museable, bien sea como material a exponer públicamente o a almacenar en espera de su revisión y estudio como material de investigación. En cualquier caso, la tutela debe hacerse efectiva, y la única manera conocida de llevarla a cabo es mediante su conocimiento, control constante y gestión de movimientos, que no se hace nada fácil para tan elevada cantidad de materiales arqueológicos.

Esta situación, vox populi entre los profesionales de los museos arqueológicos, no sería problemática para una institución cuyos espacios fueran extensibles a necesidad. Pero ello no es así, y las colecciones arqueológicas albergadas en los museos, ya numerosas, se van incrementando constantemente en el marco de un continente limitado espacialmente. Además, debemos tener en cuenta que el museo no es exclusivamente una institución públlica de almacenaje de colecciones patrimoniales, sino que es una institución pública de exposición y difusión de este material cultural, por lo que los espacios de almacenaje por lo general deberán ser porcentualmente muy inferiores frente a las unidades espaciales expositivas, y estarán amenazados continuamente por una previsible extensión de los últimos o de los espacios internos de trabajo en detrimento de aquéllos.

El elevado monto de las colecciones arqueológicas, en crecimiento constante, y la limitación espacial con la que cuentan los museos son las dos principales preocupaciones de los profesionales de los museos con respecto a su almacenaje, sin entrar en otro tipo de problemática específica, como su seguridad, niveles de conservación preventiva, etc. El actual ordenamiento jurídico y las principales recomendaciones técnicas al respecto no hacen prever un cambio sustancial en las directrices sobre almacenaje y gestión de material arqueológico en museos, por lo que es necesario refle- xionar sobre su sistematización y el establecimiento de criterios técnicos de excelencia y eficacia.

\section{Posibles soluciones al respecto}

Existen debates museológicos aún imprescindibles para el desarrollo de esta disciplina, que deberemos enfrentar en este nuevo siglo, sin perder de vista su aplicación museográfica. Para el nuevo milenio será necesario aportar nuevas herramientas que nos permitan solucionar los actuales problemas de adquisición y tutela de material arqueológico en museos, tanto por lo que respecta a la propia concepción de los materiales arqueológicos que el museo debe tutelar y aquellos no museables que pueden formar parte de otros proyectos patrimoniales, así como la posibilidad de establecer expurgos en los materiales arqueológicos ingresados indiscriminadamente en el museo.

Sotto voce comentamos los profesionales de museos estos problemas en nuestras reuniones y conversaciones informales, sin atrevernos explícitamente a plantearlo como debate serio en nuestras reuniones académicas y administrativas. Su simple planteamiento puede llevarnos a ser tildados de "terroristas del patrimonio histórico-artístico". Estas propuestas, en muchos casos enfrentadas a nuestras propias convicciones deontológicas, se palian con propuestas de solución más taimadas. El expurgo no debe ser contemplado como un "sabotaje patrimonial" o el deseo de eliminar material cultural de los fondos de nuestros museos, sino la forma de plantear con seriedad el destino de estas colecciones arqueológicas no museables, que pueden encontrar un destino más adecuado en la rehabilitación de las estructuras arquitectónicas conservadas en conjuntos arqueológicos, históricos o monumentales, en la formación de pequeños proyectos locales como arqueódromos o centros de interpretación, en la puesta en marcha de propuestas didácticas en museos tiflológicos o talleres didácticos, como material terrero para enfrentar la restauración de piezas arqueológicas museables, etc.

Actualmente, otra solución a aportar sería la de crear una distinción en nuestros almacenes arqueológicos entre los materiales que el museo puede emplear en el desarrollo expositivo y divulgativo de sus fondos, y aquéllos otros que sólo sirven para el estudio e investigación de los profesionales en esta disciplina, buscando almacenes alternativos fuera del museo para su custodia y tutela, lo que si bien solucionaría los problemas espaciales en los inmuebles museísticos, no sería tan rentable para la custodia y gestión de los movimientos de estas últimas piezas de investigación por sus técnicos. Éste es el caso de las colecciones de investigación albergadas en un gran complejo de reserva por la Smithsonian Institution, o la propuesta de almacenaje alternativo para material del Museo Arqueológico y Etnográfico de Córdoba.

Creo que, en este sentido, el primer paso a dar es el establecimiento de un Sistema Normalizado de Almacenaje, que definimos como un documento de trabajo 


\author{
Definimos un Sistema Normalizado de Almacenaje como un \\ documento de trabajo interno para la sistematización del \\ proceso que el material arqueológico sigue desde su adquisición \\ y documentación hasta su depósito en los almacenes del museo
}

interno para la sistematización del proceso que el material arqueológico sigue desde su adquisición y documentación hasta su depósito en los almacenes del museo, presidido por una normativa a establecer de forma permanente en los museos, ajena a la movilidad del personal y al criterio de cada profesional.

\section{Ventajas del empleo de un Sistema Normalizado de Almacenaje en museos}

El documento de trabajo, que constituye el Sistema Normalizado de Almacenaje para material arqueológico en museos, posee como principio base, ya apuntado al final del apartado anterior, el mantenimiento de una normativa estandarizada en el tratamiento del material arqueológico ingresado en el museo ante la multiplicidad de profesionales involucrados y su movilidad, así como al mantenimiento de una normalización de esta labor que se sitúe por encima de los distintos criterios de los conservadores que lleguen al museo. Con ello se garantiza, por un lado, la continuidad de las tareas en él contenidas y, por otro, ayuda a este personal a seguir un modelo ya establecido. No debemos suponer que anule las iniciativas irrenunciables de cada profesional, pues el documento resultante es susceptible de ser perfeccionado y cambiado periódicamente a tenor de nuevas normativas legales y reglamentarias o por nuevos criterios museográficos o académicos sobre la disciplina concernida. Esta posibilidad debe contemplarse siempre que tengamos la unanimidad de los técnicos y profesionales implicados en su elaboración y gestión, y que quede constancia de todos los cambios introducidos, por nimios que nos parezcan, en el nuevo documento de Sistema Normalizado de Almacenaje renovado.

Además, debemos contemplar la extensión de este documento normativo al resto de las colecciones, en caso de museos mixtos o con varias secciones, a fin de globalizar la normalización a toda la colección custodiada en el museo, sólo que el monto total de las colecciones restantes puede gestionarse con mayor facilidad que las específicamente arqueológicas.
En este sentido, el establecimiento de este documento de trabajo interno está recomendado por cuatro causas principales: a) la adecuación porcentual de los espacios de almacenaje en inmuebles museísticos a las necesidades de conservación y tutela del patrimonio histórico, artístico, arqueológico y etnográfico; b) la necesaria incorporación de numerosos vestigios materiales de carácter cultural tutelado por el museo; c) la informatización de los soportes documentales de las colecciones museísticas; y d) la movilidad del personal técnico al servicio de los museos.

A mi modo de ver, éstos son los principales motivos que nos inducen a enfrentar la necesaria reflexión sobre los tradicionales sistemas de gestión de las reservas, que incorporen nuevas herramientas técnicas para la mejora y optimización de los medios de almacenaje en museos, tanto por lo que respecta al espacio disponible en el inmueble para almacenar las colecciones, como por los distintos documentos que permitan una rápida y eficaz ubicación y localización del material cultural albergado en las reservas.

El primer motivo apuntado se refiere al beneficio que podemos obtener al evaluar porcentualmente el espacio del que disponemos para almacenaje, teniendo en cuenta el espacio de reserva, las específicas necesidades de almacenaje de las colecciones, la infraestructura de almacenaje que emplearemos y los necesarios espacios de circulación y tránsito de los que dispondremos en las reservas. Este cálculo del volumen necesario para el almacenaje, según las indicaciones de Johnson y Horgan, se efectuará en el momento de concepción y redacción del documento, lo que conlleva una evaluación preliminar del espacio de reserva que tendremos siempre presente en el manejo del Sistema Normalizado de Almacenaje.

El segundo aspecto apuntado como beneficio en la adopción de este documento de gestión de reservas se refiere al paulatino incremento de las colecciones, según el sistema clasificatorio utilizado en las reservas (por campañas de excavación, por colecciones, por materiales, etc.). Si bien no es una triaca contra la colmatación de las reservas, previsible en cual- 
quier caso, sí nos permite el ir incorporando las colecciones a almacenar en sus reservas de forma sistemática y preorganizada, con leves rectificaciones para casos muy concretos, evitando buscar un hueco suficiente en un rincón del almacén que no teníamos previsto utilizar. En este sentido, la evaluación porcentual del espacio destinado al almacenaje debe ser completa, eliminando espacios muertos a emplear con posterioridad como reservas.

El tercer beneficio a contemplar se relaciona con los procesos de informatización documental para museos en marcha. En concreto, el actual programa informático desarrollado en Andalucía, el paquete Odiseus, posee una base de datos para el inventario de las colecciones, el Museum, donde se recoge como uno de sus campos básicos la ubicación de las piezas dentro del museo. Este campo se ha desarrollado en árboles desplegables, donde cada unidad espacial del museo recibe un número que el sistema traduce alfabéticamente (I Almacén, 2. Exposición, 3. Oficina, etc.), que a su vez se subdividen en plantas, salas, estanterías, etc. Así, al pinchar en este sistema arborescente en el $\mathrm{I}$, dentro de éste en el 3 , dentro de éste en el 2 , y dentro de éste en el 8 da como resultado un numeral del tipo 1.3.2.8, traducido como Almacén. Planta sótano, Sala segunda y estantería 8. El Sistema Normalizado de Almacenaje nos facilitaría esta tarea, al normalizar el número de referencia topográfica, como veremos a continuación, con un numeral de este tipo con similar traducción alfabética.

Y en cuarto, y último lugar, nos permite establecer un sistema normalizado de empleo sistemático y continuado en el museo, que puede solicitar a la dirección del centro aquel técnico recién incorporado, en comisión de servicios, adscripción provisional a otro centro, externo, etc., continuando con la labor que el museo está desarrollando en la documentación, descripción y ubicación de las colecciones con las que trabaja.

\section{Sistema Normalizado de Almacenaje en museos}

El Sistema Normalizado de Almacenaje se basa en el principio general de que todo material arqueológico ingresado en el museo posee una ubicación en los locales destinados a reserva, única e irreemplazable. Para que el sistema sea integral, facilitando las tareas de control y gestión de movimiento de las colecciones, las piezas expuestas en las salas de exposición permanente deberán también tener un lugar de almacenaje asignado. Quizá podremos exceptuar aquéllas que por sus dimensiones, naturaleza y excepcionalidad posean tal inercia expositiva que no puedan ser sustraídas de su pública exhibición. También estarán exceptuados temporalmente los fondos procedentes de campañas de excavación recientes o materiales incautados en espera de resolución judicial, que se localizarán en espacios para material en tránsito hasta integrarse en las colecciones estables o depositadas en el museo.
Además, debemos tener en cuenta que los movimientos y manipulaciones de las piezas, por pequeños que sean, entrañan el principal riesgo antrópico de deterioro de los fondos museísticos, así como provoca los cambios en los parámetros higrotérmicos indicados para su conservación preventiva. En los museos debemos evitar en la medida de lo posible movimientos reiterados y manipulaciones innecesarias, y, cuando éstos sean imprescindibles, gestionar los movimientos y manipulaciones con una meticulosa planificación previa: conociendo perfectamente el estado de las piezas y los procedimientos que se especifican como los más adecuados e inocuos a su manipulación; localizando con rapidez y eficacia las piezas en los almacenes del museo, sin tener que desplazar innecesariamente otras, así como su retorno; y garantizar en todo momento que el proceso seguido es en su totalidad adecuado y seguro para la integridad física de las piezas y la salvaguarda de sus valores históricos o artísticos.

El documento debe especificar la normalización del sistema de almacenaje en los puntos siguientes:

Número de referencia topográfica para materiales arqueológicos. De todos los campos a cumplimentar en la documentación administrativa y científica del museo, uno de los más importantes es la "referencia topográfica", testigo de la ubicación de la pieza en las distintas unidades espaciales del museo y ayuda imprescindible para la correcta gestión de movimientos internos y externos de las colecciones. Es por ello que es necesario establecer un sistema normalizado de referencia topográfica.

De los numerosos modelos propuestos por las recomendaciones internacionales y la casuística nacional, proponemos la utilización de un código numérico simple, basado en la acumulación de hasta ocho dígitos acumulativos, cada uno de ellos traducción de una sección, unidad espacial o medio de almacenaje.

El dígito simple se compondrá en las unidades de reserva de : I ${ }^{\circ}$ sección del museo a la que pertenecen los materiales, $2^{\circ}$ ubicación en planta de los almacenes; $3^{\circ}$ dentro de la planta correspondiente, su área de almacenaje; $4^{\circ}$ nivel dentro del área de almacenaje, si existe más de uno; $5^{\circ}$ estantería; $6^{\circ}$ balda en la que se encuentra; $7^{\circ}$ número de la caja o pieza exenta dentro de la balda; y $8^{\circ}$ número de la pieza o conjunto de ellas dentro de la unidad de embalaje que la contiene. Así, una referencia topográfica del tipo I.2.4. I.1.2.3.2, se traduciría por: sección Arqueología (I), planta baja (2), unidad de almacenaje (4), nivel alto dentro de esta sala ( 1 ), estantería primera (I), segunda balda (2), caja tercera (3) y el segundo lote o bolsa dentro de la caja (2).

Con el fin de obtener una panorámica global sobre la ubicación de las piezas tuteladas por el museo, aplicaremos igual dígito simple a las áreas de exposición permanente, cuya diferencia con las de almace- 
naje será la consignación de sólo tres dígitos consecutivos, correspondientes a: $1^{\circ}$ sección; $2^{\circ}$ sala de exposición (no tendremos en cuenta la ubicación espacial en planta, pues la mayoría de los museos poseen un itinerario museológico con las salas numeradas consecutivamente); $3^{\circ}$ espacio que ocupa en la sala o vitrina que la contiene. En caso de gabinetes numismáticos con vitrinas sobrecargadas de piezas, podemos añadir un cuarto numeral, estableciendo un orden interno en la vitrina.

Así, una referencia topográfica del tipo 1.3.5, correspondería a la lectura: sección Arqueología ( I ), sala tercera (3) y vitrina quinta (5).

Para las piezas en exposición permanente susceptibles de movilidad entre ésta y los almacenes, consignaremos su referencia topográfica principal (exposición), así como la de reserva.

La referencia topográfica formará la espina dorsal de todo el sistema normalizado de almacenaje, y su formulación estará especialmente consignada con todos sus componentes en el nomenclator que acompaña al Sistema Normalizado de Almacenaje.

Listado de control de los almacenes. Entre los documentos que forman parte del Sistema Normalizado de Almacenaje, directamente relacionado con él para su mejor gestión de movimientos, se encuentra el "Listado de control de los almacenes", donde las distintas piezas o conjuntos de ellas almacenadas se ordenarán a través de las distintas campañas, materiales, unidades espaciales, etc. (aquél que hayamos decidido de antemano). En el listado se consignará para cada una de las unidades simples de almacenaje (pieza o conjunto de ellas): $I^{\circ}$ un número correlativo de orden, desde las más antiguas a las más recientes, ingresadas en el museo; $2^{\circ}$ sucinta descripición de la unidad simple concernida, con especificación de material, edad y cultura; $3^{\circ}$ número de Inventario General, que por la ordenación dada será correlativo de menor a mayor; $4^{\circ}$ ingreso y procedencia, especificándo el máximo de datos conocidos sobre la campaña arqueológica y el siglado de las piezas, para poder localizarlas rápida y eficazmente cuando la soliciten los arqueólogos investigadores, que aportarán normalmente los datos procedentes de la campaña de prospección o de excavación; $5^{\circ}$ su referencia topográfica; $6^{\circ}$ especificaciones de almacenaje; $7^{\circ}$ se consignará "MATERIAL SELECTO" para aquellas piezas que por su originalidad, importancia o buen estado de conservación sean susceptibles de ser expuestas o empleadas museológicamente.

Las "especificaciones de almacenaje" es un campo importante a consignar, pues nos dará noticia del estado de conservación de la pieza, así como de la forma recomendada de manipulación, embalaje y desembalaje de las piezas, que consignará brevemente en este listado de control el conservador o los técnicos responsables de la sección o del área de conservación e investigación del museo.
Etiquetado de las cajas o embalajes. Con el listado de control de los almacenes y la referencia topográfica se creará un sistema informático de producción de etiquetas, donde se consignarán los datos siguientes: $1^{\circ}$ encabezamiento de la institución; $2^{\circ}$ número de referencia topográfica; $3^{\circ}$ materiales, consignándose sección/edad/cultura; $4^{\circ}$ especificaciones de almacenaje, reproduciendo el texto breve del listado de control; $5^{\circ}$ procedencia/campaña; $6^{\circ}$ número de caja; $7^{\circ}$ número de la pieza o lote dentro de la caja (si existiese este sistema de almacenaje); $8^{\circ}$ número de estantería; y $9^{\circ}$ número de balda.

El etiquetado se adherirá a las cajas o envoltorios de las piezas por medio del procedimiento más adecuado y permanente.

Testigos de movimiento de las piezas en almacén. La base del correcto almacenaje es que cada pieza ocupe su lugar y no otro dentro de las reservas, a la vez que ese lugar no sea ocupado por ninguna otra. De ahí que establezcamos un "testigo de movimiento de las piezas", consistente en una pequeña tarjeta o cartulina donde se consignarán el número de referencia topográfica, los motivos por los que se produce el movimiento y las fechas de salida y retorno (si ésta última se conoce).

El modelo sería el siguiente: 1.2.4. I. I.2.3.2; Estudio (los motivos de movimiento de las piezas, para no crear innecesarias imprecisiones, se contendrán en el nomenclator, como: estudio/exposición temporal/ restauración/préstamo temporal/ etc.); fecha de salida; y fecha de retorno si se conoce.

El testigo de movimiento será realizado al procederse a la autorización del movimiento, se colocará al retirar la pieza y se suprimirá al volver ésta a ocupar su ubicación.

La gestión de este movimiento, cuando se realice para el estudio de los materiales arqueológicos del museo, puede completarse con la confección informática de un formulario, a firmar por el investigador responsable, para el control del adecuado movimiento de las piezas. Éste se realizará en caso de que las piezas sean estudiadas fuera de los locales de almacenaje del museo, en salas de investigación o externas al museo, por investigadores autorizados durante un dilatado espacio de tiempo. En estos casos, los materiales pueden depositarse en otras dependencias, que no son las reservas, hasta la terminación de la investigación.

No debemos entender este documento como un elemento coercitivo, aunque no debemos menospreciar su carácter disuasorio, sino como mero testigo del uso, manipulación y devolución de las piezas analizadas por arqueólogos e investigadores y tuteladas por el museo, siendo garante que el museo aporta al mismo arqueólogo e investigador de que su manipulación ha sido correcta y segura, tras la devolución de éstas al personal técnico del museo. El formulario también será garante de los derechos 
de propiedad intelectual que por ley tenga reservada la Junta de Andalucía, que el firmante acepta cumplir al introducirse a pie de página los preceptos y requisitos legales y reglamentarios que se apliquen, así como el compromiso de entrega de dos ejemplares por parte del investigador de las publicaciones que resulten de su investigación, normativa no cumplida por la mayoría de los usuarios científicos del museo. El formulario, firmado por el solicitante responsable, contendrá el número de referencia topográfica del material solicitado, los apellidos, nombre y D.N.I. del investigador responsable, el motivo por el que se solicita el movimiento, la entidad a la que se encuentra vinculado el solicitante, la fecha de inicio del movimiento y la fecha de finalización (si se conoce), con la firma de autorización por parte del director o del conservador responsable del área de investigación y conservación.

Nomenclator. La parte más interesante del documento es el nomenclator que acompaña la descripción del Sistema Normalizado de Almacenaje. En él se describirá exhaustivamente la terminología y la numeración que acompaña todo el sistema de almacenaje, con sus correspondientes herramientas documentales.
Se describirá todo el edificio (unidades espaciales de exposición y reserva, medidas de seguridad y pasivas de conservación preventiva) y el mobiliario expositivo y de almacenaje que contengan piezas o lotes de ellas, dándole un número correlativo a emplear en la construcción de la referencia topográfica. Ello se acompañará con los planos de todo el edificio, donde se reflejarán los números que les hemos dado. Así como las descripciones físicas de todo el material a emplear en la confección del listado de control de almacenes, etiquetaje, testigo de piezas y formulario de control de movimientos. Lo mismo procede con el repertorio del vocabulario a emplear para describir los movimientos, especificaciones de almacenaje, etc.

Creo que el debate sobre el almacenaje de material arqueológico en museos está abierto, debe continuarse en los foros adecuados, ajeno a demagogias partidistas y a antagonismos académicos irreconciliables, buscando soluciones a un problema tan crecido e incontrolable.

\section{Bibliografía}

AA.VV., Museum Internacional, $n^{\circ} 188$ (Monográfico dedicado a las reservas), París, ICOM/UNESCO, (vol. 47, n 4, 1995).

DOWMAN, E.A.: Conservation in field archaelogy, London, Methuen, 1970.

GODOY DELGADO, Francisco y BAENA ALCÁNTARA, Ma Dolores: "Programa museológico para la renovación del Museo Arqueológico y Etnológico de Córdoba", Museo, n 5, Madrid, Asociación Profesional de Museólogos de España, 2000, pp. I35182.

HORGAN, Joanne C.: Planning good collection facilities. Course notes to collection storage, México, D.F., Museo de Historia Natural, 1990
JOHNSON, E. Verner y HORGAN, Joanne C.: La mise en réserve des collections de musée, Paris, UNESCO, 1970 (Protection du patrimoine culturel. Cahiers techniques: musées et monuments: 2).

KNELL, Simon: Care of collections, London/New York, Routledge, 1994.

PALOMARES SAMPER, José Ángel: "Los almacenes en los museos", Revista de Museología, n I3, Madrid, Asociación Española de Museólogos (año IV, feberero 1998), pp. I31 - 137.

STOLOW, Nathan: Conservation and exhibitions. Packing, transport, storage and environmental considerations, London, Butterworths, 1987. 